\title{
Effect of Infliximab on the UVB-Induced Apoptosis of Keratinocytes Infected by HPV38 E6/E7
}

\author{
François Aubin, ${ }^{1,2}$ Tarik Gheit, ${ }^{3}$ Jean Luc Prétet, ${ }^{1}$ \\ Massimo Tommasino, ${ }^{2}$ and Christiane Mougin ${ }^{1}$ \\ ${ }^{1}$ Molecular and Cell Biology Laboratory, Université de Franche Comté, EA3181, SFR FED4234, Besançon, France \\ ${ }^{2}$ Department of Dermatology, Centre Hospitalier Universitaire, 25030 Besançon, France \\ ${ }^{3}$ Department of Infections and Cancer Biology, IARC, Lyon, France
}

Correspondence should be addressed to François Aubin; francois.aubin@univ-fcomte.fr

Received 7 January 2013; Accepted 26 January 2013

Academic Editors: M. Alaibac, S.-C. Chao, E. Pasmatzi, Y. Tuzun, and J. F. Val Bernal

Copyright (C) 2013 François Aubin et al. This is an open access article distributed under the Creative Commons Attribution License, which permits unrestricted use, distribution, and reproduction in any medium, provided the original work is properly cited.

\begin{abstract}
The question of the effect of anti-TNF-alpha in skin carcinogenesis is especially relevant in view of the increased use of these drugs for the treatment of autoinflammatory immune diseases. Since ultraviolet radiation and human papillomavirus are involved in skin carcinogenesis, we wished to investigate the effect of TNF-alpha antagonists on the UVB-induced apoptosis of keratinocytes infected by HPV38. Our results indicate that anti-TNF agent, infliximab, does not contribute to the survival of HPV38-transduced keratinocytes with UVB-induced DNA damages.
\end{abstract}

\section{Introduction}

Tumor necrosis factor-alpha (TNF- $\alpha$ ) is one of the main mediators of skin and mucosa inflammation and has a potent antiproliferative effect on normal epithelial cells. Numerous studies indicate that TNF- $\alpha$ may influence the fate of HPVinfected cells and suggest that HPV-mediated TNF resistance is a key event in the multistep process leading to cervical cancer [1].

Although several epidemiological studies have reported an increased risk of nonmelanoma skin cancer in patients treated with anti-TNF agents, the relationship remains uncertain [2]. The question of the effect of anti-TNF- $\alpha$ in skin carcinogenesis is, thus, especially relevant in view of the increased use of these drugs for the treatment of autoinflammatory immune diseases.

Besides ultraviolet (UV) irradiation which is the most important risk factor involved in the development of NMSC, cutaneous beta-HPV infection is also considered as an important cofactor [3]. Similar to the high-risk alpha mucosal HPV types, E6 and E7 oncoproteins from certain beta-HPV types target $\mathrm{p} 53-$ and $\mathrm{pRb}$-regulated pathways and display transforming activities. In particular, E6 and E7 from the beta HPV38 are able to immortalize keratinocytes that are natural hosts of the virus $[4,5]$. To our knowledge, there are no available data on the interactions between cutaneous HPV infection and anti-TNF agents.

Since anti-TNF agents are also associated with an increased risk of viral infections [6], we wished to investigate the effect of an anti-TNF- $\alpha$ agent, infliximab, on the UVBinduced apoptosis of keratinocytes infected by HPV38.

\section{Materials and Methods}

$\mathrm{HaCaT}$ keratinocytes and $\mathrm{HaCaT}$ keratinocytes transduced with empty vector pLXSN and with pLXSN-HPV38 E6/E7 vector [7] were UVB irradiated $\left(10 \mathrm{~mJ} / \mathrm{cm}^{2}\right)$ to induce apoptosis. To assess the role of TNF- $\alpha, 100 \mathrm{ng} / \mathrm{mL}$ of TNF$\alpha$ (Sigma Aldrich, Saint Quentin Fallavier, France) and $20 \mu \mathrm{g} / \mathrm{mL}$ of infliximab (MSD, France) were added after UVB irradiation. Apoptosis was evaluated by flow cytometry (annexin V/propidium iodide labelling), fluorescence microscopy and PARP, and cleaved caspase-3 western blot. Soluble TNF-alpha was measured by ELISA (Human TNF$\alpha$ ELISA MAX Deluxe, BioLegend, Ozyme, Saint Quentin, France) in the supernatants. 


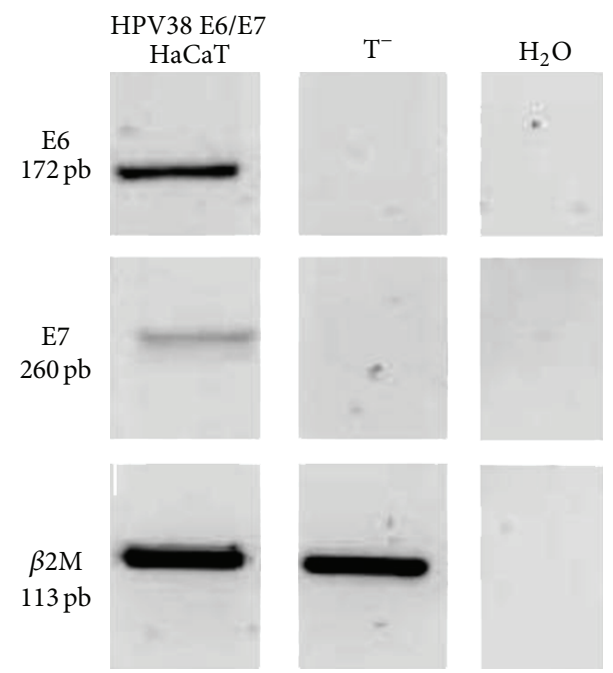

(a)

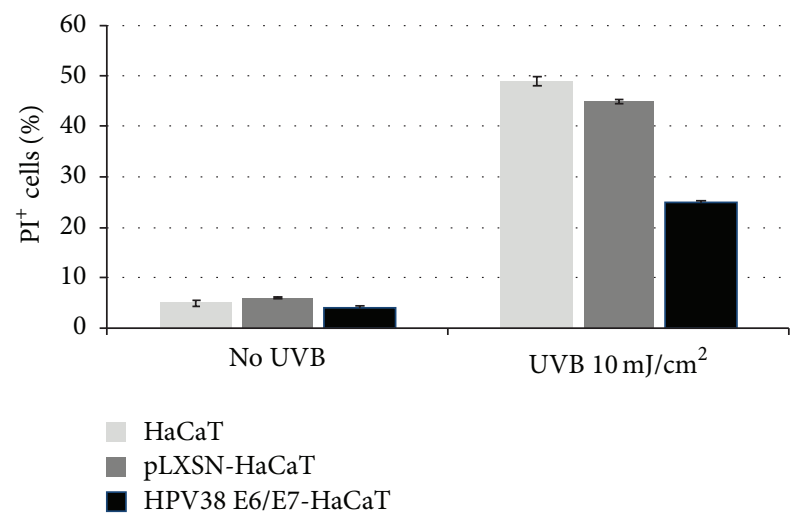

(b)

FIGURE 1: Influence of HPV38 E6/E7 expression on UVB-induced apoptosis. (a) Transduction efficiency was confirmed by RT-PCR analysis on total RNA extracted from HaCaT cells transduced with PLXSN-HPV38 E6/E7 vector. HaCaT cells transduced with the empty vector pLXSN $(\mathrm{T}-)$ were used as negative controls, respectively. $\beta 2 \mathrm{M}: \beta 2$ microglobulin gene. (b) HaCaT cells transduced by empty vector pLXSN or with pLXSN-HPV38 E6/E7 vector were irradiated with UVB $\left(10 \mathrm{~mJ} / \mathrm{cm}^{2}\right)$ and harvested 24 hours after irradiation. Then, cells were resuspended in propidium iodide (PI+ cells) for analysis by flow cytometry to evaluate the percentage of cells with fragmented DNA.

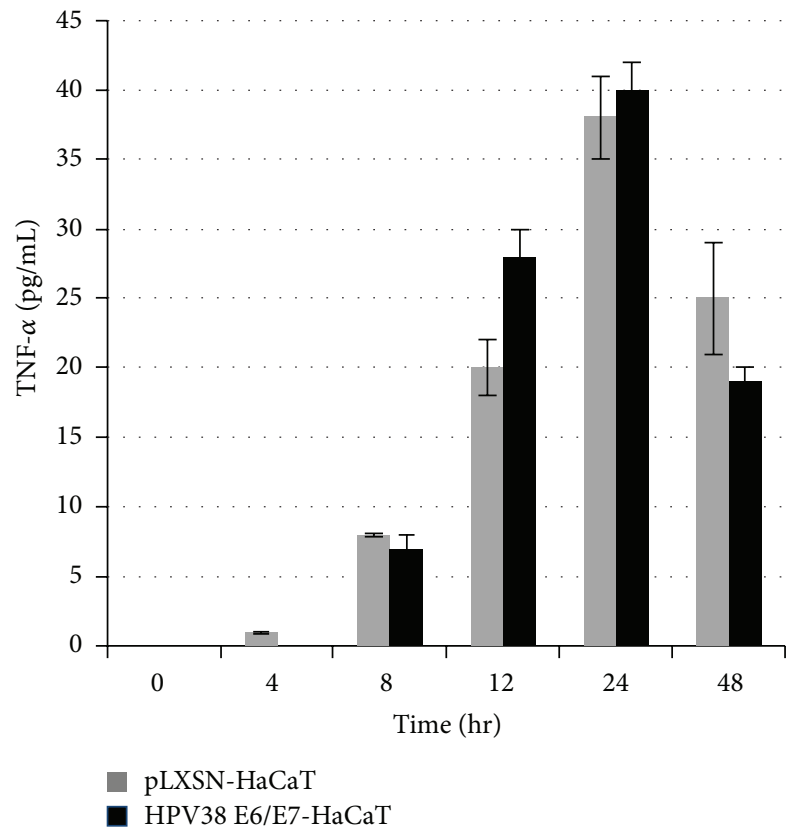

(a)

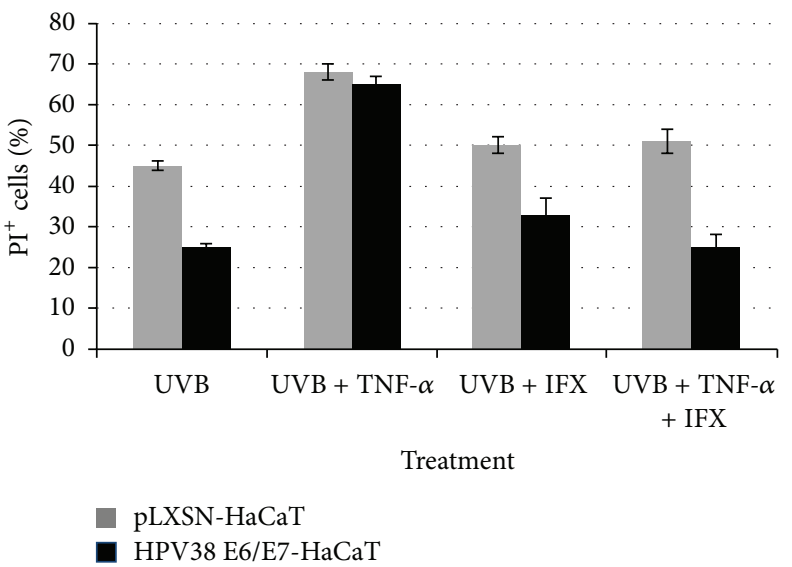

(b)

FIgURE 2: Role of TNF- $\alpha$ in UVB-induced apoptosis of HPV38 E6/E7 HaCaT cells. (a) HaCaT cells transduced by empty vector PLXSN or with pLXSN-HPV38 E6/E7 vector were irradiated with UVB $\left(10 \mathrm{~mJ} / \mathrm{cm}^{2}\right)$ and harvested 24 hours after irradiation. Soluble TNF- $\alpha$ was measured by ELISA test (Human TNF- $\alpha$ ELISA MAX Deluxe, BioLegend, Ozyme, Saint Quentin, France) in the supernatant. (b) pLXSNHaCat and HPV38 E6/E7-HaCaT cells were irradiated in phosphate-buffered saline with UVB $\left(10 \mathrm{~mJ} / \mathrm{cm}^{2}\right)$ and then incubated in Dulbecco's Modified Eagles medium with TNF- $\alpha(100 \mathrm{ng} / \mathrm{mL})$ and/or infliximab $(20 \mathrm{ng} / \mathrm{mL})$ for $24 \mathrm{~h}$. Subsequently, the cells were fixed and stained with propidium iodide (PI), and the percentage of sub-G1 cell population was detected by flow cytometry. The experiments were performed at least three times independently in duplicate. The error bars indicate standard deviation. 


\section{Results}

The gene expression of $\mathrm{E} 6$ and $\mathrm{E} 7$ in $\mathrm{HaCaT}$ cell lines was confirmed by RT-PCR analysis (Figure 1(a)). To ensure that sub-G1 population was representative of apoptotic cells, we used Hoechst staining and TUNEL assays which showed an increasing cell population with nuclear condensation and DNA fragmentation in a time-dependent manner (data not shown). Furthermore, immunoblot analysis detected cleavage of PARP and cleaved caspase- 3 following UVB irradiation in both empty vector pLXSN and HPV38 E6/E7-HaCaT cells (data not shown).

As expected [7], exposure to UVB irradiation induced HaCaT-pLXSN and HPV38 E6/E7-HaCaT cells apoptosis. However, the percentage of apoptotic HPV38 E6/E7 cells induced by UVB was 2-fold lower than those observed in HaCaT-pLXSN cells (Figure 1(b)). UVB irradiation was associated with a similar release of TNF- $\alpha$ in the supernatants from both pLXSN and HPV38 E6/E7-HaCaT cells (Figure 2(a)). Addition of infliximab $(100 \mathrm{ng} / \mathrm{mL})$ did not modulate UVB-induced apoptosis of both pLXSN-HaCaT and HPV38 E6/E7-HaCaT cells. Exposure to exogenous TNF$\alpha$ resulted in a significant increase of UVB-induced apoptosis with no significant difference in both pLXSN-HaCaT and HPV38 E6/E7-HaCaT cells. Furthermore, inhibition of TNF by the addition of infliximab $(20 \mu \mathrm{g} / \mathrm{mL})$ restored UVBinduced apoptosis level (Figure 2(b)).

\section{Discussion}

Previous studies have already demonstrated that UVB light induces the release of TNF- $\alpha$ by keratinocytes [8] and that TNF- $\alpha$ increases apoptosis in both normal human keratinocytes and premalignant $\mathrm{HaCaT}$ cells $[9,10]$. Furthermore, polyclonal rabbit anti-TNF- $\alpha$ antibody has been shown to partially reduce UVB-induced apoptosis in HaCaT cells [10]. Our results confirm recent data [11] demonstrating that HPV38 E6 and E7 expression in human primary keratinocytes was associated with a low level of UVB-induced apoptosis through the expression of NF- $\kappa \mathrm{B}$ - regulated survival factor genes favoring the survival of keratinocytes. Furthermore, the fact that we observed a lower apoptotic rate in HPV38 E6/E7 cells than in HaCaT-vector cells despite similar release of TNF- $\alpha$ after UVB exposure further suggests that TNF- $\alpha$ is only partially involved in UVBinduced apoptosis as previously suggested [10]. However, it should be noticed that the addition of high dose of TNF$\alpha(100 \mathrm{ng} / \mathrm{mL})$ restored a similar level of apoptosis in both pLXSN-HaCaT and HPV38 E6/E7-HaCaT cells. This suggests that exogenous TNF- $\alpha$ is able to suppress the inhibitory effect of HPV38 E6 and E7 expression on UVB-induced apoptosis of keratinocytes. Moreover, our results demonstrate that antiTNF- $\alpha$ agent, infliximab, does not modulate UVB-induced apoptosis of both HaCaT cells and HPV38 E6/E7-infected keratinocytes. In a previous ex vivo study, Gambichler et al. [12] observed that etanercept, a recombinant human TNF$\alpha$ receptor fusion protein, had no effect on the number of caspase-3 apoptotic cells present in skin biopsies of psoriasis patients treated with UVB and etanercept. In contrast,
Faurschou et al. [13] observed an unexpected increase of UVB-induced apoptosis in $\mathrm{HaCaT}$ keratinocytes exposed to infliximab despite enhanced G2/M cell cycle checkpoint and TNF- $\alpha$-induced apoptosis. The authors suggested a reverse signalling pathway via membrane-bound TNF- $\alpha$.

It may be argued that in our study infliximab dose $(20 \mu \mathrm{g} / \mathrm{mL})$ was too low to overcome the endogenous TNF$\alpha$ production. However, the dose tested was still able to neutralize exogenous TNF- $\alpha(100 \mathrm{ng} / \mathrm{mL})$ which induced a 2 fold apoptotic rate compared with UVB alone (Figure 2). It should also be noticed that endogenous production of TNF$\alpha$ by UVB-irradiated keratinocytes was not altered by HPV38 E6/E7 infection.

Altogether, our results indicate that anti-TNF agent, infliximab, does not contribute to the survival or the elimination of HPV38-transduced keratinocytes with UVB-induced DNA damages. Other TNF-independent pathways may be involved $[10,11]$. These results are quite encouraging in view of the increased use of anti-TNF- $\alpha$ agents in different autoinflammatory immune diseases.

\section{Conflict of Interests}

The authors state no conflict of interests.

\section{Acknowledgments}

This study was supported by Grants from the Sociéte Française de Dermatologie, the Société de Recherche Dermatologique, and the Université de Franche Comté (Besançon, France).

\section{References}

[1] E. Boccardo, C. V. M. Baldi, A. F. Carvalho et al., "Expression of human papillomavirus type $16 \mathrm{E} 7$ oncoprotein alters keratinocytes expression profile in response to tumor necrosis factor- $\alpha$," Carcinogenesis, vol. 31, no. 3, pp. 521-531, 2010.

[2] J. Askling, K. Fahrbach, B. Nordstrom, S. Ross, C. H. Schmid, and D. Symmons, "Cancer risk with tumor necrosis factor alpha (TNF) inhibitors: meta-analysis of randomized controlled trials of adalimumab, etanercept, and infliximab using patient level data," Pharmacoepidemiology and Drug Safety, vol. 20, no. 2, pp. 119-130, 2011.

[3] M. R. Iannacone, T. Gheit, T. Waterboer et al., "Case-control study of cutaneous human papillomaviruses in squamous cell carcinomas of the skin," Cancer Epidemiology, Biomarkers of Prevention, vol. 21, no. 8, pp. 1303-1313, 2012.

[4] R. Accardi, W. Dong, A. Smet et al., "Skin human papillomavirus type 38 alters p53 functions by accumulation of $\triangle$ Np73," EMBO Reports, vol. 7, no. 3, pp. 334-340, 2006.

[5] S. Caldeira, I. Zehbe, R. Accardi et al., "The E6 and E7 proteins of the cutaneous human papillomavirus type 38 display transforming properties," Journal of Virology, vol. 77, no. 3, pp. 2195-2206, 2003.

[6] S. Domm, J. Cinatl, and U. Mrowietz, "The impact of treatment with tumour necrosis factor- $\alpha$ antagonists on the course of chronic viral infections: a review of the literature," British Journal of Dermatology, vol. 159, no. 6, pp. 1217-1228, 2008. 
[7] J. S. Guerrini, V. Bouvard, E. Oswald et al., "E6 and E7 proteins from different beta-papillomaviruses types do not interfere in UVB-induced apoptosis of HaCaT keratinocytes," Experimental Dermatology, vol. 20, no. 1, pp. 71-73, 2011.

[8] A. Köck, T. Schwarz, R. Kirnbauer et al., "Human keratinocytes are a source for tumor necrosis factor $\alpha$ : evidence for synthesis and release upon stimulation with endotoxin or ultraviolet light," Journal of Experimental Medicine, vol. 172, no. 6, pp.16091614, 1990.

[9] A. Faurschou, R. Gniadecki, D. Calay, and H. C. Wulf, "TNF$\alpha$ impairs the S-G2/M cell cycle checkpoint and cyclobutane pyrimidine dimer repair in premalignant skin cells: role of the PI3K-Akt pathway," Journal of Investigative Dermatology, vol. 128, no. 8, pp. 2069-2077, 2008.

[10] A. Schwarz, R. Bhardwaj, Y. Aragane et al., "Ultraviolet-Binduced apoptosis of keratinocytes: evidence for partial involvement of tumor necrosis factor- $\alpha$ in the formation of sunburn cells," Journal of Investigative Dermatology, vol. 104, no. 6, pp. 922-927, 1995.

[11] I. Hussain, I. Fathallah, R. Accardi et al., "NF-kappaB protects human papillomavirus type 38 E6/E7-immortalized human keratinocytes against tumor necrosis factor alpha and UVmediated apoptosis," Journal of Virology, vol. 85, no. 17, pp. 90139022, 2011.

[12] T. Gambichler, C. Tigges, A. Dith et al., "Impact of etanercept treatment on ultraviolet B-induced inflammation, cell cycle regulation and DNA damage," British Journal of Dermatology, vol. 164, no. 1, pp. 110-115, 2011.

[13] A. Faurschou, R. Gniadecki, and H. C. Wulf, "Infliximab inhibits DNA repair in ultraviolet B-irradiated premalignant keratinocytes," Experimental Dermatology, vol. 17, no. 11, pp. 933-938, 2008. 


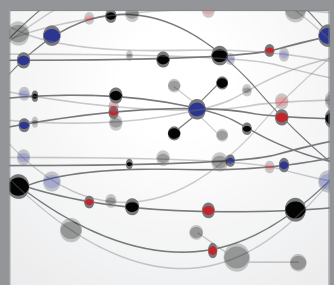

The Scientific World Journal
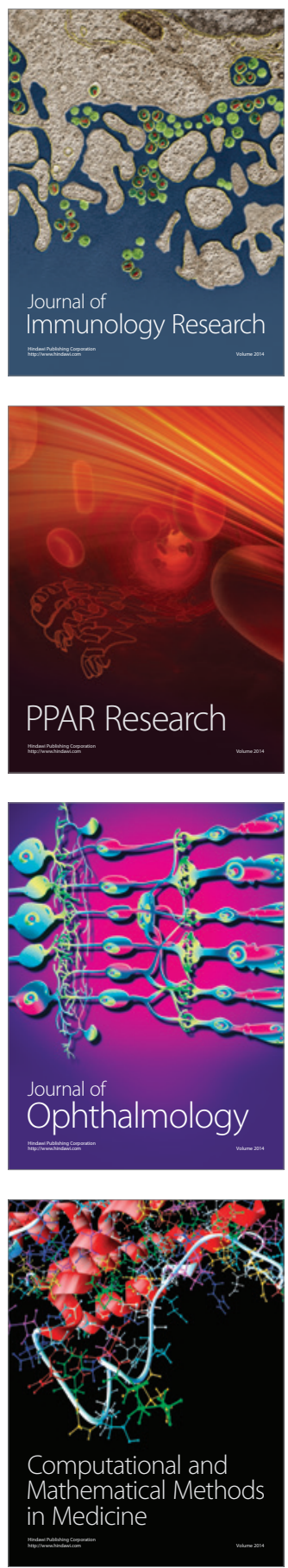

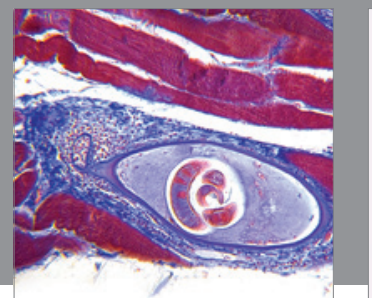

Gastroenterology

Research and Practice
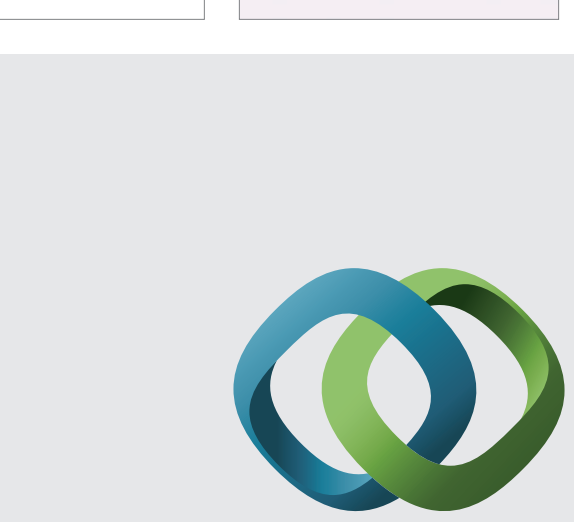

\section{Hindawi}

Submit your manuscripts at

http://www.hindawi.com
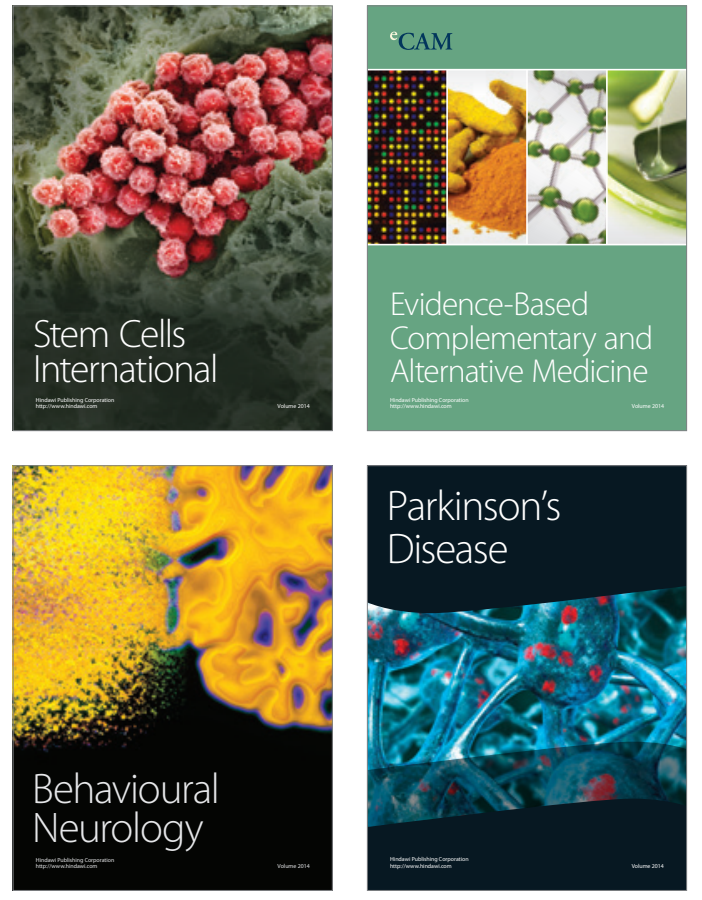
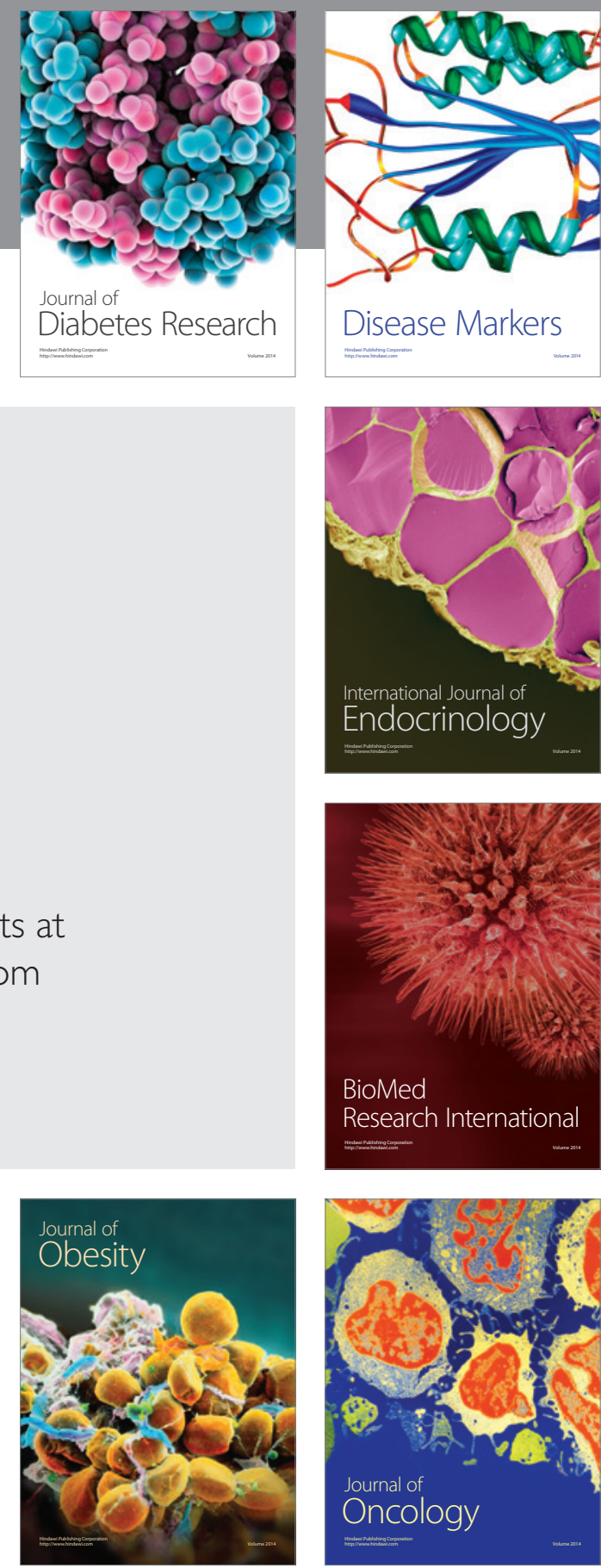

Disease Markers
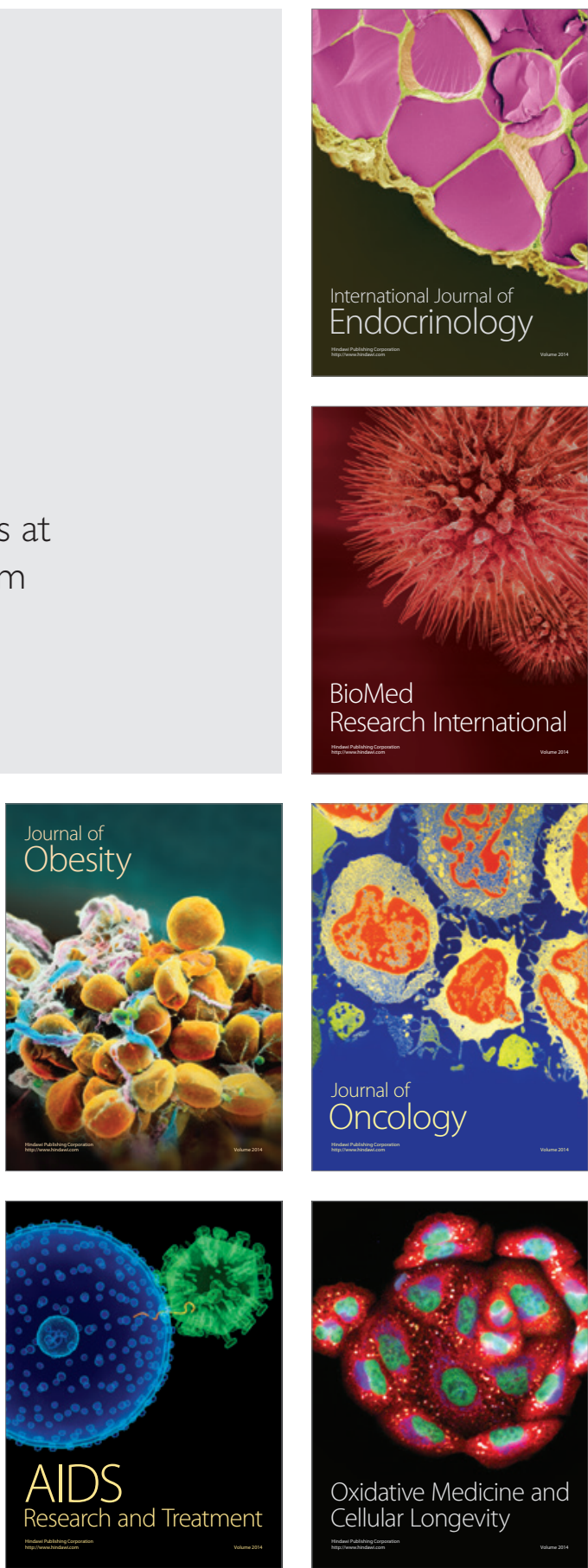